\title{
Study on Progressive Collapse Mechanism of RC Structures
}

\author{
HU Kai ${ }^{1}$, JIANG Li ${ }^{1}$, QU Ge ${ }^{1}$, LU Xilin ${ }^{2}$, LU Zheng ${ }^{2}$, WANG Peng ${ }^{2}$ \\ (1. China Shipbuilding NRDI Engineering Co., Ltd, Shanghai 200063, China; \\ 2. College of Civil Engineering, Tongji University, Shanghai, 200092, China)
}

KEYWORDS: collapse mechanism; explicit dynamics; LS-DYNA; static loading test; shaking-table test; dynamic non-linear analysis

ABSTRACT: Based on explicit dynamics numerical simulation analysis, the static loading test and the shaking-table test, and combined with the plane RC frame collapse test, the example of the highrise frame structure and the high-rise frame-core tube structure, collapse mechanism of RC structures under the static load and the dynamic load were studied respectively. Also many aspects such as the mechanical principle, the damage mechanism, the failure order and the failure range were analyzed, and suggestions on the collapse resistant design of these kinds of structures were put forward.

\section{Introduction}

In recent years, buildings collapse issues due to nature disasters(strong earthquake, strong breeze), man-made fault(fire due to fitment, pipeline explosion) and terrorist attacks(impinging, explosion) have been emerged in endlessly, such as the collapse in the $9 \cdot 11$ event, the $5 \cdot 12$ Wenchuan earthquake, the building collapse event "Loudaodao" in Shanghai and the latest event "Loucuicui" in Fenghua, China. However, once this kind of issues happen, large range of damage and serious loss of life and property would be caused. Besides, with the development of economics, engineering items become more complicated, multiplex and difficult for structural design. And after Wenchuan earthquake, the definitude requirements of preventing progressive collapse design were put forward in the Chinese new codes.

Considering the complexities of practical engineering projects and the uncertainties of accidental actions which would lead to structure collapse, these accidental actions are difficult to be considered roundly, while the study of structural collapse mechanism can provide basis for structure collapse preventing design that could help to reduce or even avoid these issues, which is of great research significance.

\section{Numerical analysis method of collapse mechanism}

In the paper, based on the design flow offered by GSA2003 and the suggestion of $<$ Code for design of concrete structures in china $>^{[1]}$ (GB50010-2010), the alternate path method was used to analyze the overall collapse process, and thus to study the collapse mechanism ${ }^{[2,3]}$. And considering the large volume and complex system of the projects, the finite element (FE) method with complete computation procedure documents was adopted as the main method of numerical simulation and the approach for mechanism study. As the structural collapse process was always accompanied by serious nonlinear problems, such as large displacement, large strain, large rotation and material nonlinearity, the explicit dynamics algorithm was choose to conduct the numerical simulation analysis with the advantages of small step size, stability and better convergence performance.

Based on the explicit dynamics algorithm program ANSYS/LS-DYNA, three kinds of numerical models as the wire-frame model, integral model and separate model were established to do the overall collapse process analysis of the RC structure for revealing the collapse mechanism of the whole structure and the failure mechanism of the regional critical components, of which the establishing methods are shown in Table 1. 
Table 1 Modeling methods of the RC EE model

\begin{tabular}{|c|c|c|}
\hline FEmodel & Modeling method of concrete & Modeling method of reinforcement \\
\hline Wire-frame model & Wire-frame & $\begin{array}{l}\text { Convert the reinforce into equiralent concrete } \\
\text { when definite the concerte material. }\end{array}$ \\
\hline Integal model & Solid & $\begin{array}{l}\text { Diffuse the reinforcement into concretet by defimite } \\
\text { the remforcement ratio to the material model of } \\
\text { concrete. }\end{array}$ \\
\hline Separate model & Solid & $\begin{array}{l}\text { Wireframe, and is joimed to concreter with common } \\
\text { nodes. }\end{array}$ \\
\hline
\end{tabular}

\section{Collapse mechanism of frame structures under static loads}

\section{The plane RC frame collapse simulation analysis}

The pseudo-static collapse test of one 3-story-4-span plane RC frame structure by Weifeng YI from Hunan university ${ }^{[4]}$ was taken as example. Based on the simplified model which is shown in fig.1, three numerical models were established, and loading mode was set according to the stepunload system as follows: firstly, the vertical displacement of the bottom node at failure point was constrained, then the gravity acceleration was applied to the whole structure and linear force uniformly from 0 to $-109 \mathrm{kN}$ was added to the top node of the middle column; keeping this loading, vertically downward step-unload displacement was applied slowly to the restricted joint, and once the displacement reached $25 \mathrm{~mm}$, the faster unloading was applied until $456 \mathrm{~mm}$. The whole process was completely consistent with the collapse test.

The central column force-unloading displacement curves of three numerical models were obtained and proved to be matched well with the test curve as shown in Fig 2.

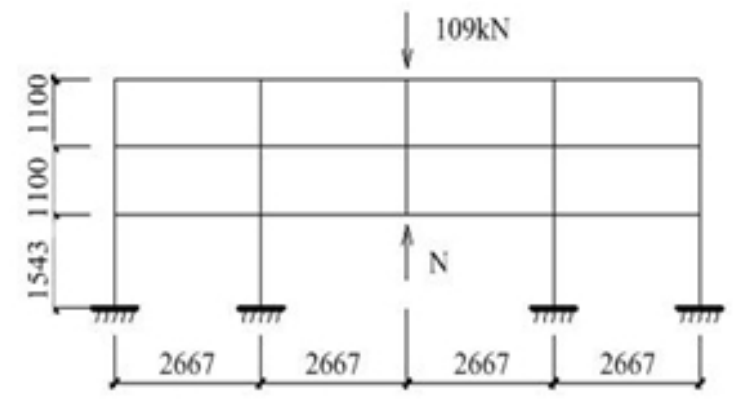

Fig.1 The simplified test model

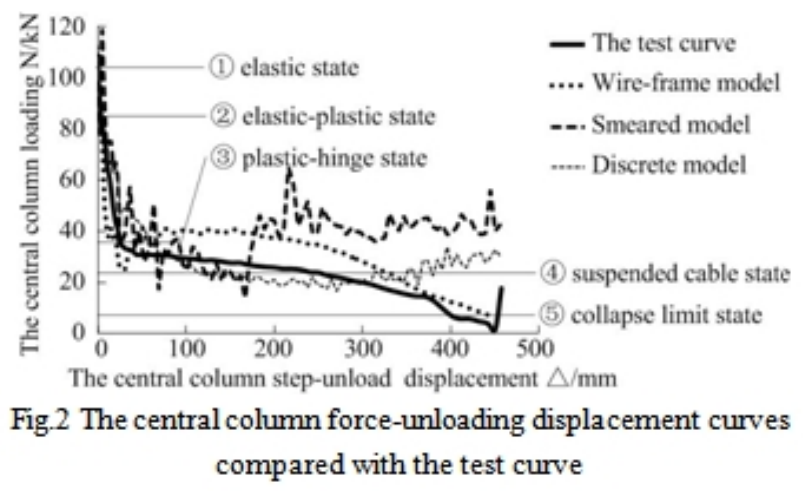

\section{Space high-rise frame structure collapse simulation analysis}

The space high-rise structure collapse simulation analysis was performed after the plane RC 
frame analysis. A 10-story RC frame structure was designed as example based on the current Chinese structure design codes ${ }^{[1,5,6]}$ with the floor dead load of $5.0 \mathrm{kN} / \mathrm{m}^{2}$, the floor live load of 2.0 $\mathrm{kN} / \mathrm{m}^{2}$, the roof dead load of $7.5 \mathrm{kN} / \mathrm{m}^{2}$ and the roof live load of $0.5 \mathrm{kN} / \mathrm{m}^{2}$, and the layout plan shown as Fig.3.

The wire-frame model, integral model and separate model were established, and under the design load, collapse phenomenon were not happen after removing the bottom layer corner column, which suggests that this high-space structure possesses anti-collapse redundancy under the static load subjected to the loss of bottom layer corner column.

To study the collapse mechanism of the space high-rise frame structure, the proposed stepwise loading start from the design load was applied, and the vertical displacement time history of the place where the column was removed of the whole loading process indicates that the collapse time and the results are almost the same of the three models, which is shown in Fig.4.

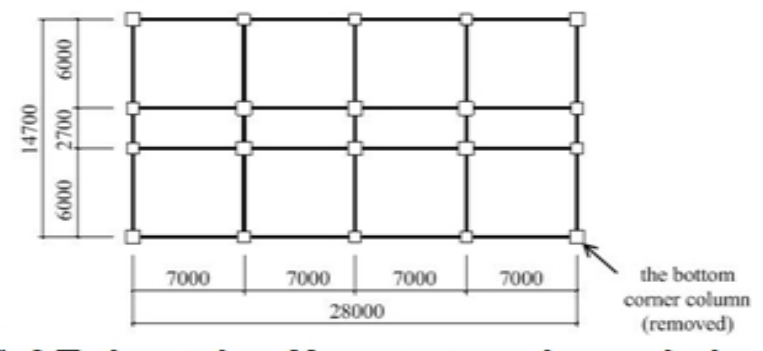

Fig.3 The layout plan of frame structure and removed column

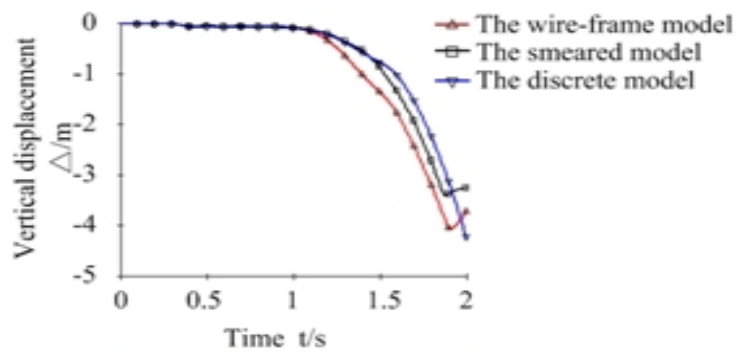

Fig4 The whole process vertical displacement time history of the place where column was removed

\section{Collapse mechanism analysis of frame structure [4,7]}

The RC frame structure collapse mechanism can be obtained by analyzing the numerical simulation results of the plane RC frame structure and the space high-rise frame structure.

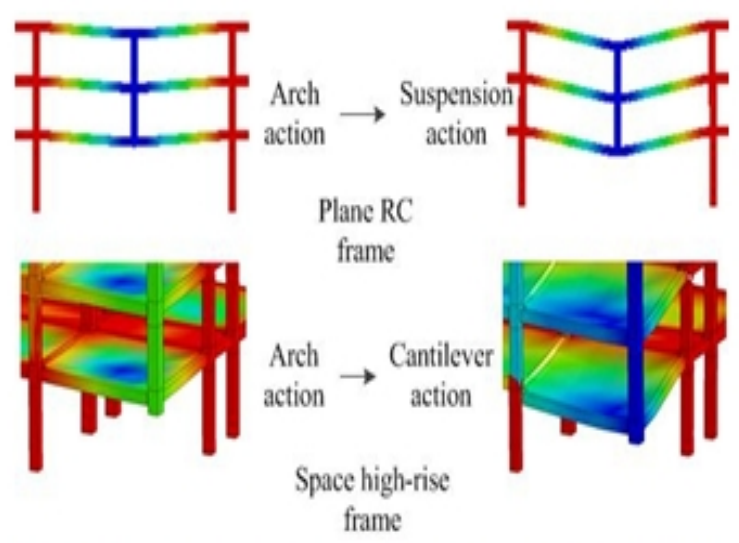

Fig.5 Deformation of the beams in the vicinity of the removed column 

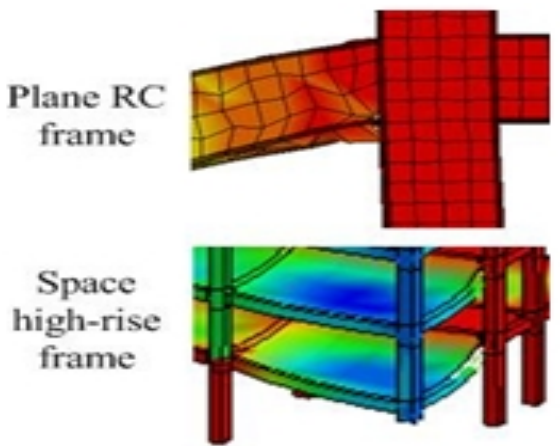

Fig.6 The local condition of the beam-end

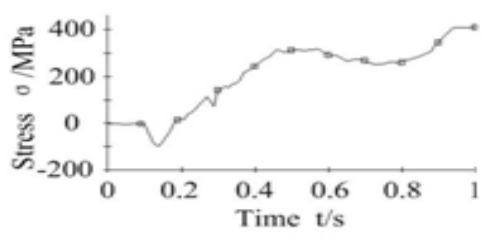

Plane frame

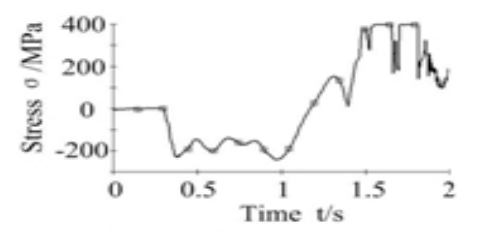

Space high-rise frame

Fig.7 The stress time-history curves of bottombar

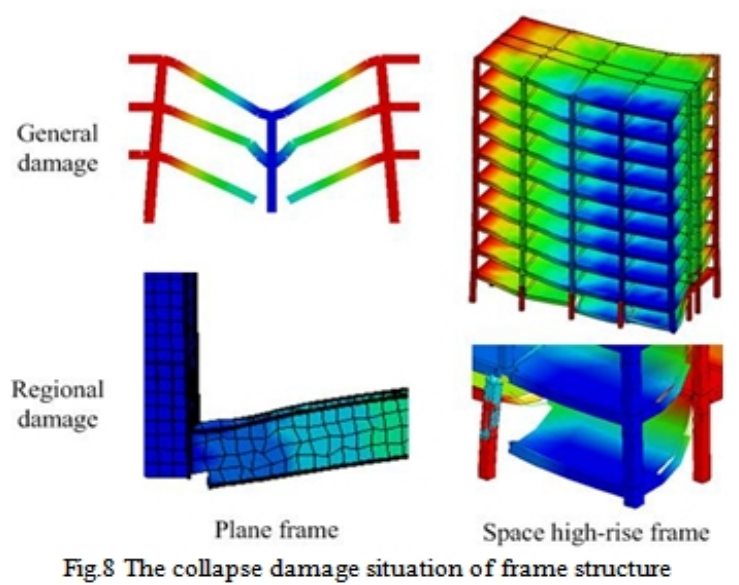

(1) Compared with the two deformation situation before the collapse of the two models (fig.5), the state of the beams in the vicinity of the removed column converted from the arch action to the catenary action obviously. Furthermore, the connection failure between horizontal and vertical component in both models and the crush failure in the space frame model were lead to the final collapse of these two structures.

(2) The local condition of the beam-end in the integral model and the separate model (fig.6) suggests that the overall collapse process was accompanied with the continuing failure of the solid element at the compression zone, which caused the loss of beam-end flexural capacity and the stress mechanism transformation of beams.

(3) As shown in fig.7, the stress time-history curve of the beam-end bottom bar in the separate model suggests that with the increasing crushed failure of the compression zone concrete, the beamend bottom bar begin to bear tensile force which means the stress state has converted to catenary action. And with the gradually increasing of load, the bottom bar finally tensile ruptured that lead to the disconnection of the horizontal components with vertical ones and cause the final collapse of the structure (fig.8). 
(4) The cause and range of the final collapse of the plane frame structure are different to the space frame structure because of the neglect of the slab effect which would enhance the structural integrity by the slab connection action and affect the ultimate failure mode of the structure, which indicates the nonignorable effect of the slab in the structure collapse simulation analysis.

(5)The collapse mechanism of RC frame structure could be conclude as follows: (1) the structure collapse is mainly because the crush of joint concrete and the rupture of steel bar; (2) the collapse process under the static loads is always accompanied with the stress mechanism transformation of horizontal components; (3) the properties of vertical components materials have significant effect on structure failure mode. So the design philosophy "strong column and weak beam, strong-joint and weak-member" has the guiding role of improving the collapse performance and controlling the collapse range.

\section{Collapse mechanism of frame-tube structures under static loads}

To study the collapse mechanism of frame-tube structures, a practical frame-tube structure project was selected for the mechanism analysis by numerical simulation and experiment study under the static and dynamic loads respectively.

Taking comprehensive consideration of the size and load capacity of shaking table in Tongji, the simplified model has been proposed for the practical engineering structure, and a 1/15 scaled 7floor test model was established based on the simplified model according to the similarity theory, of which the model layout plan is shown as fig.9, and the kinematic similarity as table 2. Microconcrete and galvanized steel wires were used as concrete and steel bar in the model, and the removed column was replaced by a jack for the simulation of the column failure during the later test. And the finished model is shown as fig. 10 .

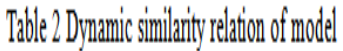

\begin{tabular}{|c|c|c|c|c|c|}
\hline Plysical quanity & Relation & Model & Plysical quantity & Relation & Model \\
\hline$\varepsilon$ & $S_{i}=1.0$ & 1.0 & m & $S_{M}=S_{p} S_{1}^{3}$ & 8888.3 \\
\hline$E$ & $S_{\mathbb{Z}}$ & 0.2 & 1 & $S_{t}=\left(S_{N} / S_{i}\right)^{n}$ & 0.258 \\
\hline 1 & $S_{1}$ & 1115 & $a$ & $S_{1}=S_{1} \mid S_{i}^{2}$ & 1 \\
\hline
\end{tabular}

\section{Collapse resistant design and Numerical simulation analysis}

To ensure the test advances successfully, the collapse resistant design subject to a corner column loss was performed first.

Meanwhile, the dynamic response of the test model under design area load were analyzed by established the wire-frame model, integral model and separate model to conduct the numerical simulation. The results show that the test model would not collapse during the tests under static loads, which guarantee the static test could proceed smoothly and the validity of collapse resistant design.

\section{Static test study}

The added mass in corresponding working condition was put on the slab before static test, and then the jack was unloaded slowly to simulate the process from the complete structure to the total loss of the corner column through the manual work. Until the force of jack was unloaded to zero, there was still displacement changing trend in the structure failure area. Half hour later, displacement change stopped and the collapse did not happen, which reflects the success of the collapse resistant design.

The static test displacement curve of the removed column position under design area load and the ones of the three numerical models were shown in fig.11, and the test result was proved matching well with the numerical results. 


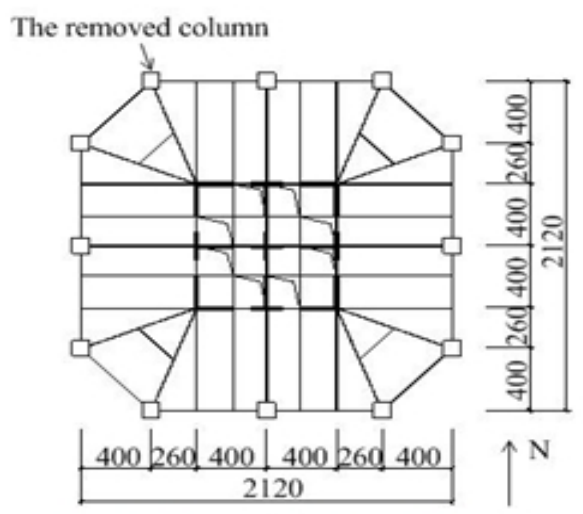

Fig.9 The model layout plan

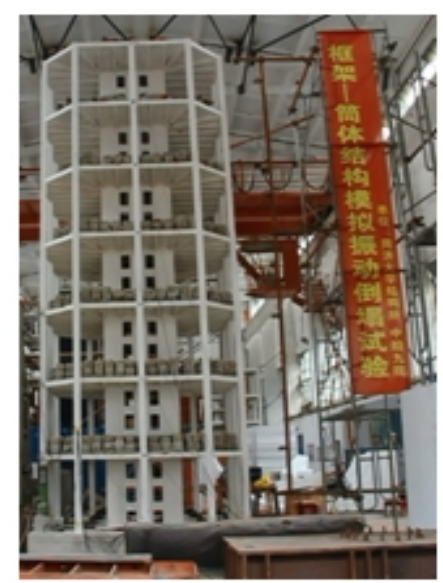

Fig.10 The finished model

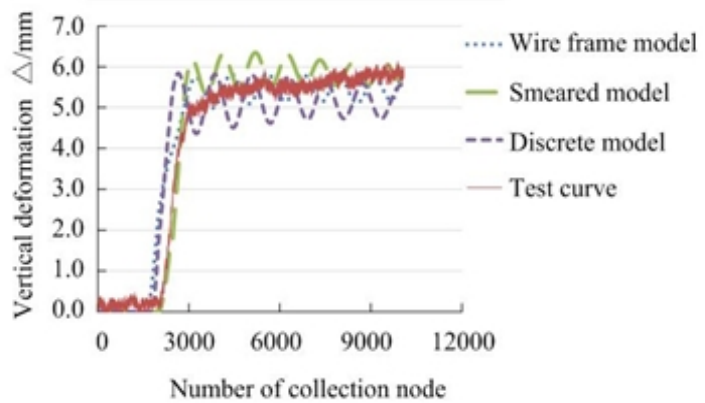

Fig.11 The displacement curve of the removed column point under design area load

\section{Collapse mechanism analysis}

In order to study the collapse mechanism of frame-tube structure under static load further, numerical simulation analysis using stepwise loading start from the design area load were conducted. Combined with the numerical simulation analysis results, the collapse mechanism study of RC frame-tube structure under static load can be achieved as follows.

(1)As shown in fig. 12, with the increasing of load grade, the beam in the vicinity of the removed column converts from arch action to catenary action. And the regional condition of the beam end in the test model (fig.13) suggests that the collapse process is accompanied with the failures of the compression zone concrete. The stress time-history curve of the beam-end bottom bar (fig.14) indicates that with the increasing of area load, the beam-end bottom bar begin to bear tensile force which means the mechanical behavior has changed. However, the catenary action does 
not last long until whole structure collapses.

(2)The collapse damage situations (fig.15,fig.16) shows that the component failure order under the static loads is as follows: the columns in the vicinity of the removed column $\rightarrow$ other columns $\rightarrow$ the adjacent shear walls $\rightarrow$ the adjacent beams $\rightarrow$ the bottom structure $\rightarrow$ the whole structure. The concrete element failure of the columns in the vicinity of the removed column causes the crash of structure column and the buckling deformation of the adjacent column. The steel bar plays a certain role of binding effect in the process of the vertical component deformation, but once the compression zone concrete is crashed, the binding effect is lost immediately. Then the failure of the bottom columns brings the structure into the final damage state. As the deficiency of one side support, the floor deformation increases significantly which causes the crush failure of the bottom layer shear walls with the result that most of bottom vertical components lose their function. Finally, the whole structure collapse under gravity loads, and the connective functions of "catenary action" are weakened by the rapid failures of vertical components.

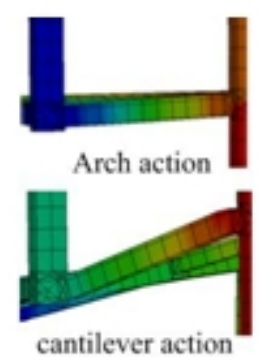

Fig.12 The deformation the beam in

the vicinity of removed column

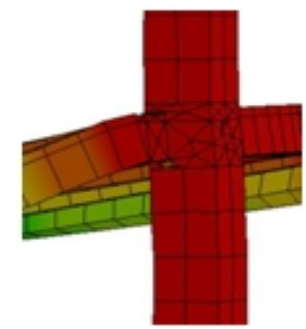

Fig.13 The regional

compression zone of beam

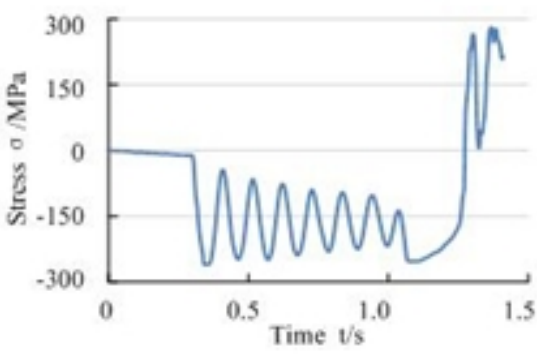

Fig.14 The stress time-history curve of

beam-end bottom bar

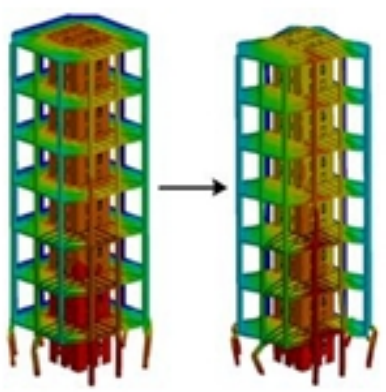

Fig.15 The general collapse

damage situation 


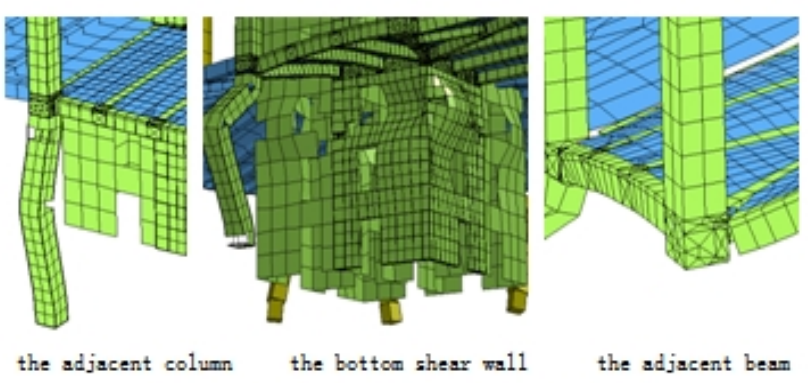

Fig.16 The regional collapse damage situation

\section{Collapse mechanism of frame-tube structures under dynamic loads (earthquake)}

\section{Shaking table test study}

After the static test was finished and stabilized, the shaking table test was performed in situ to study the damage and collapse process of the frame-tube structure subject to a corner column loss. The seismic waves - EL Centro, Taft, Wenchuan, Chi-Chi and SHW01-were chosen for twodimensional and three-dimensional input, and by stages of frequent earthquake, basic earthquake, and rare earthquake ${ }^{[10]}$ based on the requirements for 7 degree earthquake fortification and IV site ${ }^{[9]}$, as the operating case is listed in table 3. And the structure capsizal collapsed until case 31 .

\section{Numerical simulation analysis}

In order to study the whole collapse process of the frame-tube structure under earthquake loads further, the numerical simulation analysis under earthquake action was performed by inputting the design area load and the case 31 seismic wave to the numerical model with the same degree of injury to ensure that the mass and frequency of numerical model matched the ones of the test model before collapsing. And the material parameters were selected on the result of material characteristic test and test data.

Through calculation analysis, the displacement curves of structure failure area under design area load of the three numerical models were achieved, which are proximity to the displacement in the test before case 31 with the value of $18.2 \mathrm{~mm}$ as shown in fig. 17 . And compared with the test result, the whole process deformations of numerical models under dynamic loads as shown in 18 , which are proved to agrees well with the test result, with the revealing of the component failure order as the follow: the columns in the vicinity of the removed column $\rightarrow$ the adjacent shear walls $\rightarrow$ the bottom structure $\rightarrow$ the whole structure.

Table 3 the cases of seismic input in shaking table test

\begin{tabular}{cccc}
\hline The earthquake level & Frequent earthquake & Basic earthquake & Rase earthquake \\
\hline White noise & 1 & 12 & 23 \\
EL-CENTRO & 2,3 & 13,14 & 24,25 \\
Taft & 4,5 & 15,16 & 26,27 \\
Wenchuan & 6.7 & 17,18 & 28,29 \\
Chi.Chi & 8.9 & 19,20 & 30,31 \\
SHW01 & 10,11 & 21,22 & 32,33 \\
\hline
\end{tabular}

Note: Thetwo numbers in the table mean the direction of XY andXYZ.

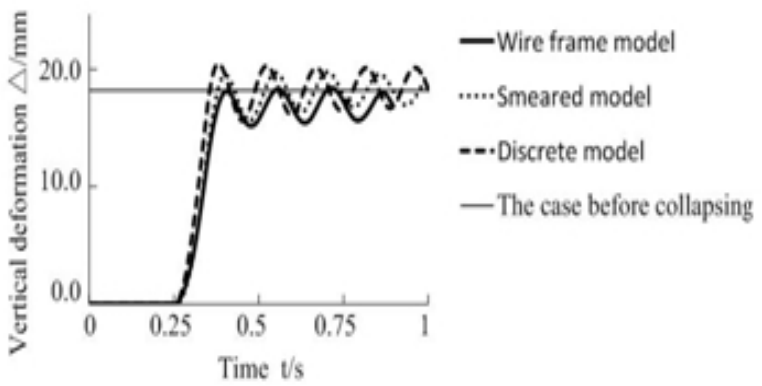

Fig.17 The displacement curves of structure failure area under design area load 


\section{Collapse mechanism analysis}

Combined with the result of numerical simulation analysis, the collapse mechanism of RC frame-tube structure under dynamic loads could be obtained as follows:

(1) The damage condition of partial components are shown as fig.19 of which the fig. 19(a), 19(b) and fig. 19(c) are arranged according to the time sequence in the order with the deep shade elements shown as the failure ones. The distribution and development situation of the failure elements in vertical members show that the failure concrete of adjacent column first appear in the column end and then extend to the whole; After the concrete of column is crushed, steel bars lose the efficacy immediately that cause the failure of the column in total cross section; with the continuing failure of the columns at the bottom layer, the deformation of the slab in these spans increased obviously, and the bottom corner shear walls and the walls in the vicinity of the outside frame columns gradually lose the function that lead to the failures of the vertical bearing component in the vicinity of the Invalid column. Finally, the whole structure capsizal collapsed.

(2) According to the beam end deformation situation of separate model (fig.20), the solid element of the beam in the vicinity of the removed column still keep working in the collapse process, which shows that catenary action does not form in beams. And the stress time-history curve of beam-end bottom bar (fig.21) suggest that although the stress state of the steel bar is transformed from compression into tension rapidly, the tensile stress is limited and in a short-time, which indicates that the pull effect is not significant.

(3)According to the collapse situation of the RC frame-tube structure under dynamic loads, the failure of outside frame columns would cause the serious failure of the adjacent vertical components and lead to the further capsizal collapse of the whole structure, as the main components of the highrise frame-cube structures to resist lateral force are the vertical components, such as, columns and shear walls, while the horizontal components, such as beams and slabs, play a role of load transferring that the catenary action is not obvious for collapse resistant capacity promotion under the seismic action or even no catenary action would form during the collapse process. So more attention should be paid on vertical components, especially in the outside frame columns and the bottom shear wall enhancement area in the design of frame-tube.

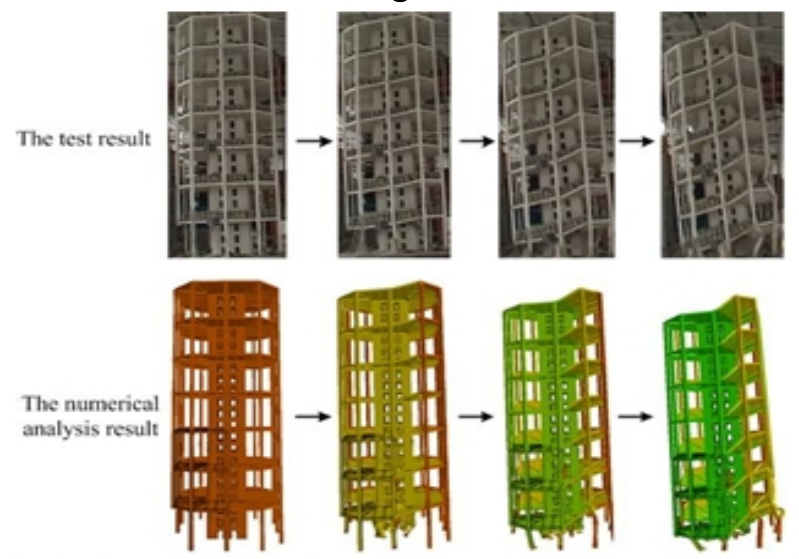

Fig.18 The whole process deformations of numerical models and test under dynamic loading 

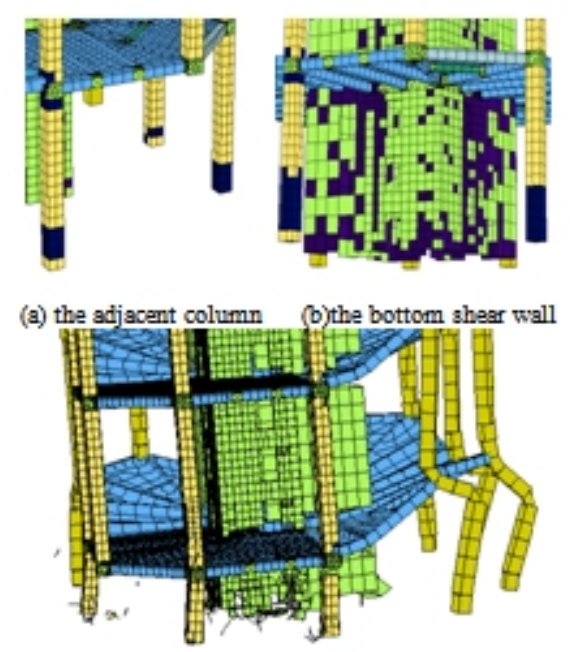

(c) the adjacent beam

Fig.19 The regional damage situation

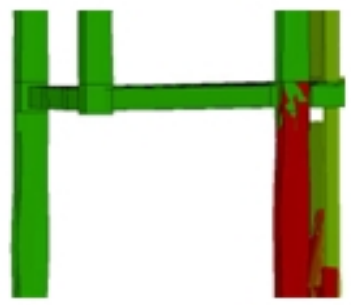

Fig.20 The beam end deformation situation of discrete model

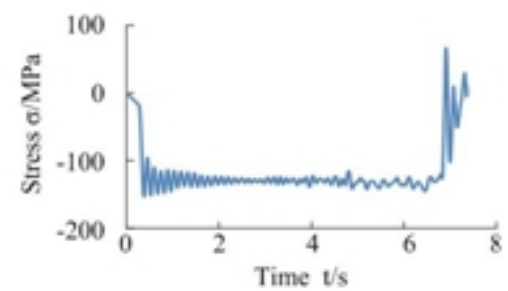

Fig.21 The stress time-history curve beam-end

\section{Conclusions and suggestions}

Based on explicit dynamics numerical simulation analysis, the static loads test and the shaking-table test, the collapse mechanism study of the plane RC frame structure, the space highrise frame structure and the high-rise frame-core tube structure under static and dynamic load were performed. On the comparison of force-displacement curve, displacement time history curve, the whole structure failure mode, the regional failure mode and test results, we can get the following conclusions:

(1)The collapse mechanism of RC frame structure and frame-cube structure reflects that the main reason of structure collapse is the joint concrete crushing and the steel bar fracture. The horizontal components mechanical behavior changed in the collapse process; the material deformation performance of vertical components affect the structure failure mode seriously.

(2)The plane RC frame structure and the space frame structure, the high-rise frame-core tube structure differs in causes and ranges of collapse. The reason of the phenomenon is that the slab effect is ignored in the plane RC frame structure model. The structure integrity is reinforced because of the slab connection action, and finally the ultimate failure mode is changed. So there is 
nonignorable effect of slab in structure collapse simulation analysis.

(3)The main components to resist lateral force are the vertical components, such as ,column and shear wall. The collapse situation of frame-tube under dynamic load shows that the outside frame columns failure would cause the serious failure of the adjacent vertical components, and further development cause whole structure collapsing. The horizontal components, such as beam and slab, play roles of load transferring. The suspension action and cantilever action are not obvious for collapse resistant capacity promotion. There is almost not any catenary under seismic action.

Based on the collapse mechanism study of RC structure, the following suggestions can be achieved:

(1)The design philosophy "strong column and weak beam, strong-joint and weak-member" has the role of guiding improving the collapse performance and controlling the collapse range.

(2)Two defensive lines should be set in structure design, especially in the design of vertical components. Once the components failed, the other ones synergistic effect can fill expressing vacancy.

(3)The collapse mechanisms of frame structure and frame-tube structure reflect that the vertical enhancing should be paid more attention in these structures designing, especially in the outside frame columns and the bottom shear wall enhancement area. There must be safety redundancy of vertical component.

\section{Reference}

[1] Ministry of Construction of People' s Republic of China. GB 50010-2010 Code for Design of Concrete Structures [S]. Beijing: China Architecture \& Building Press, 2010. (in Chinese)

[2] LIANG Yi, LU XinZheng, LI Yi, etc. Verification and analysis on foreign progressivecollapse-resistance design methods of RC frame structures [J]. Building Structure, 2010, 40(3): 8-12. (in Chinese)

[3] LU XinZheng, LI Yi, YELiePing. Theory and design method for progressive collapse prevention of concrete structure [M]. Beijing: China Architecture \& Building Press, 2011: 6-16. (in Chinese)

[4] YI Weijian, HE Qingfeng, XIAO Yan. Collapse performance of RC frame structure [J]. Journal of Building Structures, 2007, 28(5): 104-109. (in Chinese)

[5] Ministry of Construction of People' s Republic of China. JGJ3-2010 Technical Specification for Concrete Structure of Tall Building[S]. Beijing: China Architecture \& Building Press, 2010. (in Chinese)

[6] Ministry of Construction of People' s Republic of China. GB50011-2010 Code for Seismic Design of Buildings[S]. Beijing: China Architecture \& Building Press, 2010. (in Chinese)

[7] GU Xianglin, LIN Feng. New Progress in the Study of Architectural and Engineering Structural Resist Collapse [M]. Beijing: China Architecture \& Building Press, 2013: 1-9. (in Chinese)

[8] WANG Shaojie. Experimental research and analysis on the vertical collapse mechanism of reinforced concrete frame structures [D]. Shandong: Shandong Agricultural University, 2012. (in Chinese)

[9] DI Changhai, Xie Lili. The Severest Design Ground Motions for Seismic Design and Analysis of Structrues [J]. China Civil Engineering Journal, 2003, 25: 250-261. (in Chinese)

[10]HU Kai, QU Ge, ZHOU Jiangrong, etc. Study on the Dynamic Time History Analysis of CCCG South Headquarter Building [J]. Engineering Mechanics, 2013, 30(6): 253-257. (in Chinese)

[11] WANG Xinzheng, LI Ping, YANG Wenxi, etc. Damage Evolution of Concrete Filled Steel Tube By Lateral Impact with Numerical Simulation. Engineering Mechanics, 2013, 30(6): 267272. (in Chinese) 